\title{
Hard, Soft, Smart? North Korea and Power: It's All Relative
}

\author{
VIRGINIE GRZELCZYK*
}

\begin{abstract}
North Korea is notable for its isolation, yet the Korean Central News Agency's daily editions are filled with articles outlining international admiration for Pyongyang and its leader. Is Pyongyang actively promoting soft power as an integral part of not only its survival, but its development strategy? While scholarship on North Korea tends to focus on Pyongyang's "high profile" relations with China or Russia (Shambaugh 2003, McCormack 2004, Wu 2005) or with nations seeking to cooperate on weapons of mass destruction (Henriksen 2001), little attention has been paid to how the DPRK engages in seemingly peaceful ways with the world. This article examines the notion of hard, soft, smart and other power declensions, and applies a soft-power framework to investigate DPRK rhetoric and the development of partnerships with both states and non-state actors. It suggests that the DPRK has long pursued a strategy of diplomatic diversification, which includes a more sophisticated understanding of power than previously considered in the literature.
\end{abstract}

Keywords: Soft Power, Hard Power, DPRK, North Korea, Public Diplomacy, Balancing

* Senior Lecturer, Aston University, Birmingham, United Kingdom;

E-mail: v.grzelczyk@aston.ac.uk;

DOI: 10.16934/isr.18.1.201706.131 


\section{INTRODUCTION}

From its inception on 15 August 1948, the Democratic People's Republic of Korea (DPRK) has been engaged in a war of survival. The North Korean struggle to exist is political and has centered for many years on the question of which Korea was the more legitimate entity to manage the entire peninsula. So, the Koreas competed politically, attracting international support and playing off one another until they each became equals as members of the United Nations in 1991. Yet, they still square off over an unresolved armistice and a Demilitarized Zone cutting the peninsula in half. The North Korean struggle to exist is also ideological, with a ruling system inspired by Marxist-Leninist approaches and a spirit of self-reliance and independence, as embodied in the ever-encompassing Chuch'e principles. Clinging to Communist ideas after the Soviet Union collapse has alienated the DPRK, marginalizing it to the periphery of the international system. The North Korean struggle to exist is, intrinsically, about its system and its basic economic model, which has suffered from estrangement as old trading partners vanished or joined new trading blocks. It has also suffered from a domestic political crisis with the construction of a cult of personality surrounding Kim Il Sung, and the imperatives needed to sustain loyalty upon his death, and the death of his son Kim Jong Il. Finally, the DPRK's existence has suffered because of input and output mismanagement, inclement weather, and international sanctions. This has now created a catch-22 situation: Pyongyang's desire and perceived needs to ensure its survival has led to its military buildup and the development of what it claims is a defensive nuclear weapons program. As a result, the international community has sanctioned and isolated the country. With trading partners slowly disengaging from existing deals, and few opportunities to exchange funds via the international banking system, North Korea appears relatively powerless in our globalized world, yet still manages to, as Marcus Noland had already suggested 20 years ago, "muddle through" (1997, 117). This does not mean that the DPRK has been completely isolated and impervious to the international system, however. While a large part of the scholarship on the DPRK focuses on military might, nuclear weapons programs and the security dilemma, a growing number of studies consider a more critical approach and question the foundations of our understanding of how the DPRK operates. This means that questions of power and energy are no longer treated from the standpoint of the United States and its own security needs. Instead, many scholars support the thesis that the DPRK is a rational actor and that it is possible to analyze the DPRK using a number of International Relations lenses. Hence, this article considers the question of soft power and its articulation, and applies it to the DPRK to further our understanding of how Pyongyang functions and how one might tackle the question of North Korean survival. Essentially, the article questions the assumption that soft power appears to be a relatively inefficient approach to defusing 
tensions and crisis on the peninsula.

Our argument is that the notion of soft power has often bypassed the DPRK, and has only considered how soft power has been applied to the DPRK, and not how the DPRK itself has used soft power. The suggestion here is that soft power waged onto the DPRK has had to contend with Pyongyang's own strategic narrative and its own attempts to project soft power. In order to present these findings, the article proceeds in three steps. First, it considers a classic understanding of power and how soft power has slowly been accepted as a different kind of power, one that utilizes public diplomacy to complement hard power usually based on military might. Second, the article presents a more refined understanding of soft power, one that highlights three directions that particularly pertain to the DPRK's situation: (1) the concept of defensive soft power, (2) the idea of improving one's image via virtual enlargement and (3) the hope to develop a niche diplomacy that will allow for growth. Third, the article considers the DPRK's situation by focusing on the classic "soft power in the DPRK context" narrative that sees Pyongyang only as a target of soft power, before analyzing how the DPRK has utilized soft power itself in a defensive manner, to manage its image abroad and more recently to seek growth opportunities and improve its economic situation. Ultimately, the article suggests that there are no cheap and easy options to foster change on the Korean peninsula, but that engaging the DPRK on matters of economic development at the public level might yield better results over time given the inflexibility of the elite.

\section{THE DEBATE OVER POWER}

\section{Classical Understanding}

In Soft Power: The Means to Success in World Politics, Joseph Nye compares the concept of power to the weather, stating that everyone always talks about it yet few really fully understand it (2006). Power is at the core of our international system, whereby actors will seek to "advance particular sets of political, economic or other interests," and "the interests that are favored by this arrangement reflect the relative powers of actors involved" (Gilpin 1981, 9). In this configuration, it is clear that just about any actor will be concerned with questions of power, relative or absolute. While power pertains to all actors, questions of power have centered around the notion of capabilities and for classical realists such as Hans Morgenthau, power covers anything from the physical to the psychological control of one onto another (1985). Power is therefore a physical capacity, and especially a military quantity that allows for the projection of force. With the end of the Cold War, the International Relations field has refocused the debate away from those "hard" capabilities to consider economic power as well. In this arena, Susan Strange's work on structural power 
and especially the relationship between markets and political authority has been central (2015). Thus, power could allow anyone to impose their own values by designing a system that is hegemonic in nature, and that does not necessarily involve military capabilities (Cox 1983). What this means is that the field has shifted from a traditional understanding of power as military might, one that often times implied the maintenance of hegemony. Instead, we can now consider a more pluralistic understanding of the notion of power, and one that is far from involving only coercive capabilities. This means that small and medium-able states do not always matter less within the system: while they would have, long ago, been considered unable to challenge an established hegemonic order because of their lack of critical military capabilities, they now are seen as possessing, at times, unique and useful assets too (Woehrle 1992). From education to culture to mediating talents, those states tout a different kind of power, one that Joseph Nye called "soft power" in his seminal book, Bound to Lead (1990).

\section{From Hard to Soft Power}

Joseph Nye has delivered a concise definition of soft power as "the ability to affect others to obtain the outcomes one wants through attraction rather than coercion or payment" $(2008,94)$. Yet, the notion of power has been visited and revisited by many prior to this particular iteration. While Foucault or Gramsci developed a notion of soft power based on structural forces, Nye proposes three prime resources that create the foundation of soft power: culture, political values, and foreign policies $(2008,97)$. When combined with the English language as a unifying medium within the international world, soft power becomes a vehicle to be shared, and for countries such as United States, results can be obtained without the use of coercion (Rose 2005). However, it is also easy to return to the notion that soft power could be used within hegemonic constructs: soft power, according to Janice Mattern, manifests itself via attraction, or a relationship that, while not being physical, is exercised through language, and could also potentially be coercive (2005).

Soft power studies have focused primarily on how Washington can use different attributes, and the field has often centered on the concept of the American way of life, how it is promoted through culture and products, and especially why American values are seen as attractive. Further political categories involving aid and ODA also allow for a more fluid and encompassing approach to power. This has to some extent shifted the agenda away from the United States onto how other states, be they small, medium, or large, manage to impose their ideas as well. At times, soft power can also be generated within institutions, especially those with a global reach. It also means that states that are often isolated or that have isolated themselves from the international system might be at a disadvantage when it 
comes to appearing legitimate and engaged in fostering cooperation.

Ultimately, soft power is not about the absence of force, or more broadly an alternative to the usage of the military, but it is about knowing how and when to use carrots instead of sticks (Hackbarth 2008). This is done by creating a "medialized approach" in that soft power is exercised in a nexus that incorporates state foreign affairs, the media, public relations and an audience (Plavsak 2002). This requires two components. First, the creation of a communication structure, as exemplified by how the United States has been engaged, for the better part of the past two decades, in developing regional media hubs in the Middle East, in order to speak on America's behalf (Kroenig, McAdam, and Weber 2010). Second, the development of a compelling strategic narrative that relies on actors, space and stage: the strategic narrative can clearly identify how the world is structured and who the players are, but also operates at the national level to clearly explain the story of a nation, its people, values and goals (Roselle, Miskimmon, and O'Loughlin 2014). When these elements are combined, and when they operate within a receptive and functioning marketplace of ideas, they help support a specific issues narrative that a state wants to pursue using soft power attributes. Incidentally, the choice of target is crucial: soft power can be considered "high" when it targets the elite, and "low" when it targets the general population of a specific country (Hackbarth 2008).

\section{Soft Power and Public Diplomacy}

Although soft power centers around state actors, it operates in a pluralistic environment that involves more than state constituents. As a result, soft power is often practiced via public diplomacy. Edward Murrow defined the term in 1963, while he was heading the United States Information Agency under President Kennedy. For Murrow, public diplomacy was about the interactions with foreign governments but more importantly with non-governmental actors such as people and institutions and organizations (Nye 2008). This often creates, at least in the case of public diplomacy practiced by a democracy, two spheres: "the stateto-public" sphere in which governments seek to explain their politics and activities to the public, and the more recently developed "public-to-public" sphere that involves NGOs, the media, or universities (Kalin 2011). Regardless of which public diplomacy sphere one focuses on, Nye stresses the important of maintaining regular communication explaining contexts and decisions, of developing a more precise strategic communication that focuses on specific themes, and of sustaining relationships with most of the stakeholders at hand. But in the end, soft power and public diplomacy do not develop overnight. They require continued engagements with the international environment as well as developed communication channels. 


\section{SOFT POWER: FROM THEORY TO PRACTICE}

\section{Refined Usage}

While the original soft power idea is well understood in the literature, it also raises a number of questions that have led to a flourishing debate on the nature of actors, the messages delivered and received through soft power enterprises, the interplay between soft and hard power, or how to simply measure an actors' soft power potential. A number of private agencies have been busy producing soft power rankings, and Portland Communications, with a foreword from Joseph Nye, uses culture, food, sport, as well as political concepts such as governance and more recently digital diplomacy as variables to provide a top-thirty ranking. The 2015 results featured the United Kingdom as leading the pack, swiftly followed by Germany, the United States, France and Canada. China closes the ranks at the $30^{\text {th }}$ place (McClory 2015). Just as any other enterprise that seeks to put a value on the nature of power, much of the scholarship has focused on tools and resources and their derived and projected capabilities. This means that the study of soft power is often focused on counting beans instead of clearly analyzing processes through which soft power really operates. This is especially true when it comes to looking at the concept of soft power beyond the perimeter of its most talked-about user, the United States. Just as scholarship and analysis of capabilities often revolve around how great powers yield their resources, the study of soft power has only started to scratch the surface, and considers how smaller, and in some cases even states that have been labelled rogue states, might also be using soft power means to sustain and develop themselves. Hence, the concept of soft power has gained considerable traction because it allows for the participation of a broad amount of actors within the system as well as the opportunity to make progress, without necessary spending too much because citizens do not need to go to war: the cost of entering into soft power activities is therefore cheaper than engaging with hard power (Mattern 2005). A practical example often revolves around data and book exchanges, or sometimes termed "high culture," which is seen as a low-cost and easy approach to foster profound change within a particular society, as was demonstrated by a few initiatives via the Asia Foundation in North Korea (Park and Bennett 2014). The concept also allows for actors to transcend their limitations: states such a South Korea or South Africa would be unable to become regional powers because of the interplay between complex historical legacies and geographical and resource limitations, yet through international branding, they are able to maximize their economic gains (Kalinowski and Cho 2012). Ultimately though, what matters is using power smartly. Ernest Wilson reunifies various strands of power, especially the hard and soft varieties, by defining smart power as "the capacity of an actor to combine elements of hard power and soft power in ways that are mutually 
reinforcing such that the actor's purposes are advanced effectively and efficiently" (2008, 110). It then becomes imperative to consider more refined interpretations of soft power, and especially interpretations that depart from the view that all usage of soft power is "positive" and for the greater good, peace and harmony (Loh 2017). Recent works that consider soft power as defensive power, soft power as image shifting and soft power as niche diplomacy represent new articulations particularly helpful to the study of the North Korean case.

\section{Harder Ways to Consider Soft Power? Soft Balancing and Defensive Soft Power}

What becomes of soft power when an actor's purpose is, at its core, about survival and how to maintain a specific status within the system? For the People's Republic of China, the concept of soft power has been about pursuing hegemony. Some have suggested that this hegemonic quest is benign, and it articulated along the "smile diplomacy," or "good neighbor diplomacy" with hosting the Olympic Games often cited as an important step for China (Finlay and Xin 2010). Others have concentrated on China's new role as a donor country, providing development aid, although a case could be made that this is an economic venture to develop relationships rather than an altruistic journey (Hsiao 2009). It is the Confucius Institutes system, however that has often embodied China's quest to spread its soft power and appeal to an international audience that is interested in culture and education, one of the core soft power resources highlighted by Joseph Nye. But when writing about the then-novel phenomena of the Confucius Institutes, whose numbers have now passed 100 around the world, James Paradise suggested that the enterprise was as much about disseminating information about China to improve its image abroad than it was a political design (2009). For one, Confucius Institutes have created tensions when being created in international settings as they adhere to Chinese laws, a point that is sticky when it comes to academic freedom and the potential interference of Chinese officials into academic affairs of a foreign country (Callahan 2015). The notion of soft power within the Chinese context is, indeed, somewhat different from what is usually accepted within the Western sphere, as it incorporates the concept of subduing an enemy without having to fight (Wang and Lu 2008). So, some have suggested that China is using soft power in a defensive manner by making a conscious effort to engage with and refute attacks made on China's image, while at the same time ensuring that the press also runs "ambivalent" articles about China so as to give the impression that the coverage is balanced (Loh 2017). China has also been seen as yielding "negative" soft power: instead of using soft power as a foreign policy tool, Beijing is actually more concerned about domestic policies and regime legitimacy (Callahan 2015). This means that the Chinese soft power enterprise becomes about the development of a narrative about China and how it operates in the world, with 
the goal to unifying and crystalizing the PRC as one country (Finlay and Xin 2010). This does make sense given the contentious relationship between mainland China and Taiwan. Taiwan has a different interpretation of soft power, one rooted in political institutions and diplomacy as opposed to Beijing's view that Chinese soft power rests on traditional Chinese culture (Wang and Lu 2008). Russia is in a similar situation when it comes to using soft power to re-establish its lead over the former Soviet region: Moscow might be exercising soft power as a form of imperialism (Tsyganov 2006). Both China and Russia have also been engaged, at times, in soft balancing against one particular state, the United States. Other states such as Venezuela have also engaged in similar activities, with a clear policy under Hugo Chavez to develop relations and alliances with Cuba or Iran, and organize anti-US summits (Corrales 2009). Eventually, the United States has to use soft power to counterbalance a number of threats and conflicts: musical diplomacy has been used to induce a change in the US-DPRK relationship (Cathcart 2009) while more recent efforts have focused on the Middle East and changing how Iraqis perceive Washington in order to assuage the US-led Iraqi occupation (Kroenig, McAdam, and Weber 2010).

\section{Smarter Ways to Consider Soft Power? Virtual Enlargement and Shifting Image}

Some nations such as India have naturally capitalized on innate soft power values such as non-violence or democracy (Wagner 2010). Soft power has also been used in the context of changing one's image from one that might have been problematic in the past to a new one that is deemed more seductive, more attractive, and in some cases less threatening. France created the Alliance Française in 1883 as a way to project French culture at a time when the French government had just suffered a defeat in the Franco-Prussian war and needed to reestablish its relationship and image (Nye 2008, 96). The question of shifting image is often very much tied to the environment and history, and states have had to rewrite a specific narrative in order to reframe their own history and place within a particular system. Hence, Iran's usage of soft power has changed over time, from focusing on its civilization and heritage prior to the 1979 Revolution to be overtly about Islam, with Ayatollah Khomeini's "neither East nor West but Islamic Republic" slogan (Wastnidge 2015). Qatar, too, is currently attempting to dispel potential negative views of the Middle East and especially the notion of instability in the region by hosting the Soccer World Cup (Grix and Brannagan 2016). Japan, as a reformed colonial power is also attempting to promote a soft power image via the popular Japan Exchange and Teaching Program (JET), the increasing use of Overseas Development Assistance or the usage of manga and anime. It has done so to propagate the idea of "Japan Cool" but also to reframe its usage of the military: anime characters have been painted on some of the non- 
combat troops military equipment Japan has used in Iraq (Lam 2007). Yet, this promotion attempts to mitigate Japan's image and other political actions related to history, such as the difficulty to negotiate around the question of comfort women, for example. In this particular context, Japan also competes on the soft power plane with other countries such as South Korea, which has replicated a similar strategy to Japan with the will to brand South Korea and the development of manhwas, or hallyu as federating cultural forces in Asia and beyond. Given that Seoul was a victim of Japanese colonialism, it has a definite advantage since it does not have to fight against the remnant of the image of an aggressor. But propagating soft power through a particular national image can also be problematic if other countries find this particular offensive: anti-China sentiments have been noted in Japanese mangas by the Chinese press (Lam 2007). Because soft power relies heavily on proper communication channels and cultivating a receptive audience, it is key not to alienate others: Hugo Chavez' social power engagement, and especially his will to polarize opinion, was seen as problematic for potential clients who wanted to not just be rhetorically involved with one another (Corrales 2009). Thus, the "negative" side of soft power has not always been analyzed. But just like any policy, the soft power approach is not just a benign tool and the advent of communication techniques online means that it is now very difficult to hide a public protest or a political backlash against prying electronic eyes (Loh 2017).

\section{Unique Ways to Consider Soft Power? Niche and Growth Diplomacy}

Branding as part of a niche diplomacy is also becoming an increasingly diversified way to engage in soft power activities. South Korea has made significant effort to create a specific branding to engage with the international community and to cement its position as a middle power with clout within the system. It has been argued that developing a brand goes beyond consumerism, and must engage with societal values as well (Cull 2012). However, there is a healthy dose of skepticism surrounding the ROK's branding strategy as this strategy is seen as overtly mercantilist (Kalinowski and Cho 2012). In this light, Seoul's strategy is much less about spreading values than it is about securing a number of Free Trade Agreements and providing Overseas Development Assistance to enhance its standing. Seoul has also been seen as stepping up its notion of sovereignty and territorial integrity by engaging in border tourism: this is clearly represented through Seoul's development of the Demilitarized Zone, as well as the narrative it has built around the Dokdo islands. Ultimately, there is a sense that the Republic of Korea is still fighting the ghost of Japanese power and invasion, while simultaneously being engaged in a war of division over the peninsula given the unresolved nature of the Korean conflict. So, nations must often be able to carve 
themselves a specific niche within the diplomatic world if they want to exert soft power; for this particular aspect, development is a popular field. Brazil, for example, has engaged in solidarity development cooperation, and evidence has shown that a more positive image of Brazil amongst aid recipients has formed not on the basis of what has been achieved via the project but more on how the management and relationship between entities and individuals were developed and sustained (Bry 2015). The development of a style, of a presence and of a voice is also what Norway has been recently cultivating. For a small state of only 5 million people, and a speaker of a different language than English, it has managed to present an image to the world that it is a peaceful force to be reckoned with (Nye 2008). Lastly, Cuba is another atypical player that has flirted with isolation and conflict with the United States, and has often touted its soft power approach with its worldwide exports of Cuban doctors and nurses (Corrales 2009).

\section{NORTH KOREA'S SOFT POWER CONTEXT}

The question of power has always surrounded the Korean peninsula, but never fully on the DPRK beyond its nuclear and missile proliferation. A survey of the literature shows intense engagement in analyzing how the DPRK has slowly build a rocky albeit still surviving socialist system (Gills 1992; Chun 1984; Kihl and Kim 2006). There is also an important focus on the concept of potential reunification (Bleiker 2005; Harrison 2003; Armstrong 2005). However, most scholarship has focused on the security dilemma surrounding the Korean peninsula because North Korea was seen for many years as being on the brink of collapse (Bennett 2013; Oh and Hassig 1999). The past two decades have seen an extraordinary amount of work done on North Korea's hard security matters, and by association on how the United States and Asian regional powers can contend with North Korea's missile development as well as its nuclear weapons program (Albright and Hinderstein 2006; Van Ness 2003; Sigal 1999; Kwak 2010). In all these discussions, the will of the DPRK has often been left aside, and North Korea treated as an object within this particular security dilemma, a problem to be tackled and solved, with the immutable belief that the state of Korean affairs should return to a pre-division era, and with North Korea's system and survival being described as an anomaly in our international system. It is only recently that a more critical reading of Korean affairs has entertained the idea that the DPRK was not nearly as irrational as previously depicted, and not nearly as on the brink of collapse as it might have been in the 1990s (Smith 2000; Byman and Lind 2010; Frank 2012). In the end, hard power has been discussed, but soft power only marginally considered in the context of the DPRK as being the target of soft power efforts, for it was not quite conceivable that an alienated, rogue and violent regime might have the means and the will to consider using soft power in any way, shape or form. 


\section{The DPRK and Soft Power: A Conventional Story}

The DPRK's relationship with soft power is mostly depicted along Nye's lines: it is about how to use culture and attributes in places where it might be attractive to others, political values at home or abroad, and foreign policies that might be seen as having moral authority. Within these perimeters, soft power initiatives in the DPRK have centered on a few events that have been held as examples of success, and often heralded as processes that should be reproduced, and that would eventually become agents of change within the DPRK society. Foreign policy soft power initiatives separate from the government have not featured at all since just about any activity initiated by foreign powers on North Korean territory is subject to political scrutiny and would have most likely been stopped.

Activities involving political values have taken place during the 2000 meeting between Kim Dae Jung and Kim Jong Il, and the initiative to organize family reunions for those who had been separated many years before by the Korean partition and the Korean War. ${ }^{1}$ Soft power used in a cultural context has been more visible: the opening in 2004 of the Goethe Institute reading room in Pyongyang, ${ }^{2}$ the 2008 New York Philharmonic Orchestra concert in Pyongyang, and the visit in 2013 of basketball player Dennis Rodman and his meeting with Kim Jong Un are the more prominent examples. ${ }^{3}$ All those initiatives vary in their messages, but they also all share a similar element as they have been targeted at the two levels described by James Hackbarth (2008): low-level targeting with the Korean people, and high-level targeting with the Korean elite. They have, in both cases, represented effort at socialization, a process by which the "other side" can slowly be known and potentially understood (Saunders 1991). The seemingly brotherly connection that was shown with Kim Dae Jung and Kim Jong Il's historic hug and handshake in 2000 was important for the Korean people as a whole. The Philharmonic concert broadcasted in the DPRK humanized Americans and North Koreas to one another, and connected them while playing music that could apparently be enjoyed by both parties, despite the fact that some music choices might also have provided for a hidden and subversive meaning, at least on the American part (Cathcart 2009). The basketball meet performed a similar function, and proceeded, for a moment, to humanize Kim Jong Un as a person enjoying a simple game: the message was also important to the rest of the world, suggesting that if a connection could be made around a simple ball, then surely the rift between the DPRK and the United States could not be that deep. Suffice is to say that in light of the more recent rounds of nuclear testing, basketball diplomacy has failed to gain many 3-pointers.

The Goethe Institute initiative was part of a project that dovetailed with highculture and education partnerships, a strand of engagement that has become more 
sustained and visible in the DPRK over the past decade. But back in 2004, the Goethe Institute was the first Western reading room in Pyongyang. The DPRK and Germany negotiated book content, censorship was not permitted, and access to resources had to be granted to anyone in North Korea. ${ }^{4}$ The Institute closed in 2009 after the DPRK failed to provide internet access and allow unrestrained access to the population: the culture aspect of the collection, which was embodied in a number of literature and music books, was of little interest to a North Korean elite that wanted more technology, science, and medical resources. ${ }^{5}$ This simple fact shows that the DPRK is most likely less interested in variety and novelty as it is interested in specific technical resources: a strategy player concerned with its survival, the DPRK is known not to trample upon its red line, and to pull out of a deal if it becomes unsatisfactory and high risk to the survival of its elite (Snyder 1999).

What is clear is that these initiatives did not provide a catalyst for further change, and especially for the resolution of complex hard-power dilemmas. The assumption that soft power is unsuccessful when used "against" the DPRK is perhaps the most problematic point here: in Western minds, the success of such initiatives would end with the Kim family downfall and essentially the collapse of the North Korean government, leaving the population to be absorbed by the South. This is a strategic narrative that has been cultivated for many decades by the United States and its allies, first within the context of the Cold War and the fight against Communist ideas, and then within the context of North Korea's illicit nuclear weapons program. The problem is that strategic narratives run both ways: the DPRK is an expert and master at soft power (with a hefty dose of policing as well) in its domestic context, where a strategic narrative about survival, about enemies, and about how the DPRK leaders are the only hope to provide guidance for the country to survive and thrive has been developed for many years and coerce an entire population. These strategic narratives include political values, foreign policy goals and strong cultural elements. This brings us back to the concept of defensive soft power, and especially how North Korea operates similarly to China, which has been using elements of soft power to ensure national cohesion (Loh 2017). This also means that while the DPRK controls its soft power technique, it is more knowledgeable about the potential impact of foreign initiatives that bring soft power to a number of cultural and educational areas. Though the hierarchical and top-down nature of the North Korean regime might suggests that the DPRK does not necessarily know the difference between organizations, NGOs, private-citizens and state-sponsored educational enterprises, this thesis has been refuted (Zhebin 1995): the DPRK has always interacted with a number of actors since the Cold War, it has also joined 28 intergovernmental institutions and has experienced varied engagements with the NGO sector during the 1990s with the World Food Program, and a number of projects funded by the European Union (Ślusarczyk 2010). 
Thus, the main puzzle remains about what soft power initiatives could potentially foster change and modernization in the DPRK, but within the perimeter of the Kim family retaining their hold on power. Knowledge-sharing approaches in the fields of food security, public health, medicine or agriculture, but also business and international law might provide the start of an answer (Park and Bennett 2014). Initiatives by Syracuse University a decade ago have been followed by new schemes by Singapore-based Choson Exchange to teach business, in the DPRK, to citizens and in some cases exclusively to women, while Canada's University of British Colombia has hosted North Korean university professors for extended periods. PUST, Pyongyang University of Sciences and Technology which was launched in 2010 is the first private and foreign university to operate in the DPRK. ${ }^{6}$ But in all these cases, the DPRK is still a recipient of soft power. Yet, a reading of contemporary North Korea within the context of how soft power is created provides alternatives: under such a lens, Pyongyang's structures and policies could be those of a soft-power emitter itself.

\section{Reframing Soft Power beyond the Mundane}

While there is a general assumption that small and poorer nations are unable to really contribute to the international system and its management (Chasek 2005), it has also been argued that small states, because of their particular historical contexts, decision-making processes and general negotiation behavior, might have considerable clout within the international system after all (Zhu 2007). Marrying these arguments to how soft power is defined allows for looking at the DPRK under a new lens: possessing soft power and being able to administer it means that military and hard capacities matter less than previously thought (Melissen 2005). The DPRK, because of its weapons development, already possesses what is, in the end, a Joker card in the form of a nuclear deterrent. Nuclear weapons also involve the concept of prestige, at least for poorer nations that look at the North Korean example and imagine it as representing success. If Janice Mattern talks about the importance of attraction in yielding soft power (2005), then the DPRK might be able to provide a narrative that is attractive to lesser powers; it might have succeeded in developing what Lynne Woehrle called "unique and useful assets" (1992). In this case, this means nuclear weapons and a capacity to keep the superpower United States at bay, and thus tapping into the anti-hegemony movement. Venezuela's own actions in developing relations with Cuba and Iran, and also organizing anti-United States summits, show the world that it might be possible to engage in offensives that are delivered via soft power initiatives. We also know that soft power can change over time, and be based on different attributes. Iran prior to the Islamic Revolution based its soft power on its civilization and heritage, while the Revolution led to a stronger focus on Islam and 
a will to remain neither part of the East not the West (Wastnidge 2015). This construct is similar to the DPRK's decision to play the PRC and the USSR against one another in the 1960s, while it developed its own narrative based on independence and non-interference.

More importantly, the DPRK fits snuggly into Kristina Plavsak's "medialized" approach as well, whereby a state needs to operate within a nexus that connects its foreign affairs to the media and eventually to an audience (2002). Here, the DPRK has developed since 1946 and the creation of its state-own media Korean Central News Agency an outlet that communicates the Workers' Party of Korea's views to a wider audience, along with the leadership's views. Considering the DPRK as a potential source of soft power means that any ventures will most likely be initiated by the state and thus the elite, and will fall within the state-to public realm of action, which is described by Ibrahim Kalin as the sphere in which governments attempts to explain their activities and politics to the foreign public and audience to gain power and influence (2011). When looking at the KCNA, a foreign-focused media enterprise, and how it communicates about the world, several categories appear: a spectrum extends from closeness with countries such as China, to antagonism with the United States and Japan. A content analysis of the KCNA's data, available from 1997 to 2015, for 192 states, shows that the DPRK, via the KCNA, consistently talks about a large number of countries, but more importantly it also engages with domestic actors that are not always official governments such as political groups, education enterprises, culture entities, and in some cases private citizens. Only a few dozen countries never appear in the DPRK's media frame. For the others, there are various and gradual engagement modes:

- "Greetings, Congratulations and Condolences" whereby the KCNA is used as a diplomatic tool to send congratulations to countries and people to celebrate their national holidays, leaders' elections, independence anniversaries as well as commiserate on deaths and disasters.

- "Hope for Relations," a "back-burner" category used by the DPRK to suggest that relationships could develop further, perhaps past the point of greetings and congratulations to reach a delegation exchange state.

- "Delegations" where the DPRK expands on diplomatic engagement, and delegations are sent and received.

- "Protocols and Agreements" whereby the DPRK presents cooperation enterprises, especially in the fields of culture, technology and education.

- "Memorandum of Understanding and Defense Agreements" usually falling along close historical partnerships.

However, if the DPRK appears to possess the nexus to spread soft power, it does not mean that it is able to attract others and compel them to do what is wants. Indeed, the DPRK has a strategic narrative that has been developed around its 
quest for survival, the Chuch'e ideology and more recently its commitment to its economic independence and sovereignty in a world that is globalized and capitalized. Yet, this strategic narrative is hampered by North Korea's military development, its nuclear tests and the nature of its regime. Finding the right target audience in a functioning marketplace of ideas (Kroenig, McAdam, and Weber 2010) for a strategic narrative developed in these conditions and by this specific actor remains a challenge.

\section{CONCLUSIONS: NORTH KOREA'S SMART POWER GAME?}

Defensive soft power, image management and enlargement and growth/niche diplomacy represent the three broad soft power enterprises with which the DPRK has been engaged. Because of the DPRK's Kim leadership, the human rights abuses, general instability and irrationality associated with the Korean peninsula and North Korea, there are serious limitations to the soft power capacities that the DPRK can produce, and can broadcast. As Alan Chong puts it, small isolated states such as Sierra Leone, Fiji, Cuba or even North Korea would need to develop their economy and social capital exponentially if they wanted to virtually enlarge their presence the way Singapore has managed to, for example (2010). For authoritarian states such as the DPRK or Iran, Joseph Nye's soft power model is used upside down: while soft power is usually a bottom-up enterprise led at the grass-root levels by non-state actors, soft power for Pyongyang or Tehran starts at the top and trickles down lower, and the message is established by the leaders, and propagated through the media (the KCNA for North Korea, or the Islamic Republic's international media outlets for Iran), before the message is nurtured at times on foreign grounds by outreach centers (Wastnidge 2015). For states such as North Korea, non-state actors abroad can at times disseminate ideas. This is the case for Chuch'e study groups, national chapters of Korea Friendship Associations, and far left-wing groups with connections to Pyongyang that are particularly active in Spain, Italy, and Poland. ${ }^{7}$

Defensive soft power is a prominent feature for the DPRK. It is articulated, at times, via the DPRK's engagement in global governance. North Korea's participation in a number of international organizations has often been utilized to defend the DPRK's right to exist, usually in defiance of the ROK. This has been the case within the UNESCO, where the DPRK has promoted a successful bid to list a number of ancient tombs and Koguryo murals to the status of World Heritage sites, ${ }^{8}$ including its own version of the traditional song Arirang. ${ }^{9}$ But the real North Korean soft power weapons is articulated via the KCNA. The KCNA communicates in ways that is similar to Dylan Loh's China own defensive soft power techniques (2017): "fact-like news reporting" that essentially promote the DPRK's image and address criticisms of its system from other countries and actors, and other articles that project a positive 
image of the DPRK via projects and engagements. While the former is usually wellknown and labelled as North Korean propaganda, the latter are broad in scope as they focus on education, culture, the arts and technology, and involve partners that are not always traditional (i.e not only former USSR satellites or the PRC). These include:

- November 2008: Agreement on cultural cooperation between DPRK and Qatar

- December 2008: Cooperation agreement between DPRK and Czech Republic

- March 2010: Signature of cultural cooperation agreement between DPRK and Gabon

- March 2010: Signature of plan for cultural cooperation agreement between DPRK and India

- November 2010: Signature of inter-government pan for culture between DPRK and Indonesia

- March 2012: Unhasu Orchestra gives performance in Paris

- April 2012: Signature of 2012-2014 plan for cultural exchange between DPRK and Vietnam

- April 2012: Education Partnership with Canada

- April 2012: Performance of Ukrainian Dance Troupe in Pyongyang

- April 2012: Joint internet homepage opens in Kuwait

- May 2012: Korea-Norway joint concert in Pyongyang

- September 2012: Joint scientific conference opens

- November 2012: Joint DPRK-German concert

- November 2013: Working pan for cultural cooperation between DPRK and Egypt

- May 2014: Cultural exchange plan signed between DPRK and Bangladesh

- July 2014: Plan for cultural exchange signed between DPRK and Cambodia

Improving and enlarging one's image is the second important theme for the DPRK in its usage of soft power. This image shifting has been done through a retooling of some of its own capabilities, as well as the promotion of its own country, architecture, and assets as vehicles for power. The capability of retooling pertains to the role of the military, as mentioned by Haluk Karadag, and means that forces could be seen as public agency and no longer just a tool of oppression (2017). The DPRK has been involved in police, taekwondo and military training for a number of years, especially in Uganda where cooperation in the field has been ongoing for more than three decades, ${ }^{10}$ though it has recently come under scrutiny by the United Nations as part of sanctions that prohibit military training. ${ }^{11}$ The promotion of the DPRK's own natural beauty and facilities has started to become more visible. While the KCNA often calls for foreign investments to support the development of tourist 
industries, the domestic tourism industry developed in partnership with a number of foreign organizations has meant that a sizable number of foreigners have visited the DPRK. Tours take place around the DPRK's important events such as Kim Il Sung's birthday, or the Pyongyang marathon. The financial incentive is important for the DPRK as allowing foreigners in means that foreign currencies can be raised directly (American dollars, Chinese Yuan and Euros are routinely accepted in the DPRK). However, the DPRK has also been projecting its image abroad via food. The establishment in Europe of the Pyongyang Restaurant, a joint venture between two Dutch Businessman and North Korea opened in Amsterdam in $2012^{12}$ and there are similar ventures located in China, though the 2016 group staff defection from a Beijing North Korean restaurant brings us once again back to the nature of the North Korean regime and the difficulty it has to blur the reality of its citizens' treatment. ${ }^{13}$

Niche diplomacy and especially promoting growth and to some extent pleasure and happiness abroad is an unusual proposition when associated with the DPRK, but represents a developing area for Pyongyang. The DPRK soft power is seen, yet to some extent hidden in its architecture abroad, and especially in Africa where the Mansudae overseas division, an offshoot of the Mansudae Arts Studio which build monuments, fresco and other art pieces to support the DPRK's propaganda domestically has been particularly active in building large museums, memorials, statues, and state houses. The art has a distinct North Korean feel, and has made North Korea a popular choice for historic monuments, especially because of their relatively cost-effective value. ${ }^{14}$ The DPRK has also used its museum know-how and has assisted the Tanzanian military building in Dar es Salaam in 2008 with art displays. ${ }^{15}$ The latest North Korean museum venture is available in Cambodia, at the Angkor Wat temple site where tourists can visit the Panorama museum, which houses an animated 360-degree fresco representing life during the Khmer empire. ${ }^{16}$ The revolving viewing platform is a copy of the platform showing a fresco of the Korean War at the National Liberation Museum in Pyongyang. While it is not possible to know the full intention behind the DPRK's engagement with such monuments and trade, it appears that the power connection factors very little. For Pyongyang, the monuments represent an interesting cash flow and the Panorama museum is expected to provide a steady income stream of about $\$ 150,000$ to the DPRK through ticket sales alone. ${ }^{17}$ With United Nations Security Council Resolution 2321 adopted in late 2016, the future of North Korean statue and monument exports might be compromised, since they are now outlawed by the resolution. ${ }^{18}$ Yet, there is still some mileage in North Korea's soft power efforts. A decade ago, North Korea followed the Cuban medical personnel example efforts by signing a deal with Zimbabwe. Under the agreement, North Korean doctors would staff hospitals to mitigate the effect of the brain drain that has seen doctors seek better job in South Africa or in the United Kingdom. ${ }^{19}$ More recently, the DPRK has exported ginseng and the practice of 
acupuncture to Mexico. ${ }^{20}$

While it is difficult to fully embrace the notion that the DPRK is an exporter of soft power given the fact that its political values and attractiveness to others is quite limited, the relationship between Pyongyang and soft power is a two-way street. Evidence shows limited support for the notion that soft power can radically be exported to one country or onto one actor and change its behavior. To this extent, even military power often fails to achieve such a feat. But there are many shades to the notion of soft power, and to the reasons why specific countries might engage in public diplomacy. Soft power can have an impact in North Korea when taking the form of high culture and education, but with the understanding that the North Korean government still mans the boat, and controls its population through a tight police system and a strategic narrative that leaves little leeway to radical change from the bottom-up. With economic indicators showing a slow economic upturn in the DPRK despite many sanctions, ${ }^{21}$ the focus of soft power applied to the DPRK should be about supporting its modernization to enable a better livelihood for its future generations.

\section{REFERENCES}

Albright, David and Corey Hinderstein. 2006. Dismantling the DPRK's Nuclear Weapons Program: A Practicable, Verifiable Plan of Action. In Dismantling the Democratic People's Republic of Korea Nuclear Weapons Program. Washington, DC: United States Institute of Peace.

Armstrong, Charles K. 2005. "Inter-Korean Relations in Historical Perspective." International Journal of Korean Unification Studies 14(2): 1-20.

Bennett, Bruce W. 2013. Preparing for the Possibility of a North Korean Collapse. Santa Monica, CA, USA: RAND Corporation.

Bleiker, Roland. 2005. Divided Korea: Toward a Culture of Reconciliation. Minneapolis: University of Minessota Press.

Bry, Sandra. 2015. "The Production of Soft Power: Practising Solidarity in Brazilian South-South Development Projects." Canadian Journal of Development Studies / Revue Canadienne d'Études du Developpement 36(4): 442-458.

Byman, Daniel and Jennifer Lind. 2010. "Pyongyang's Survival Strategy: Tools of Authoritarian Control in North Korea." International Security 35(1): 44-74.

Callahan, William A. 2015. "Identity and Security in China: The Negative Soft Power of the China Dream." Politics 35(3-4): 216-229.

Cathcart, Adam. 2009. "North Korean Hip Hop? Reflections on Musical Diplomacy and the DPRK." Acta Koreana 12(2): 1-19.

Chasek, Pamela S. 2005. "Margins of Power: Coalition Building and Coalition Maintenance of the South Pacific Island States and the Alliance of Small Island States." Review of European Community \& International Environmental 
Law 14(2): 125-137.

Chong, Alan. 2010. "Small State Soft Power Strategies: Virtual Enlargement in the

Cases of the Vatican City State and Singapore." Cambridge Review of International Affairs 23(3): 383-405.

Chun, Yong-Hon. 1984. "Political Socialization in North Korea." Vantage Point.

Corrales, Javier. 2009. "Using Social Power to Balance Soft Power: Venezuela's Foreign Policy." The Washington Quarterly 32(4): 97-114.

Cox, Robert W. 1983. "Gramsci, Hegemony and International Relations: An Essay in Method." Millennium 12(2): 162-175.

Cull, Nicholas J. 2012. Global Trends and Middle Power Practices of Public Diplomacy: Implications for Korea. Korea Public Diplomacy Forum.

Finlay, Christopher J. and Xin Xin. 2010. "Public Diplomacy Games: A Comparative Study of American and Japanese Responses to the Interplay of Nationalism, Ideology and Chinese Soft Power Strategies Around the 2008 Beijing Olympics." Sport in Society 13(5): 876-900.

Frank, Ruediger. 2012. "North Korea After Kim Jong Il: The Kim Jong Un Era and Its Challenges." The Asia-Pacific Journal 10(2 no. 2): 109-129.

Gills, Barry. 1992. "North Korea and the Crisis of Socialism: The Historical Ironies of National Division." Third World Quarterly 13(1): 107-130.

Gilpin, Robert. 1981. War and Change in World Politics. Princeton, NJ: Princeton University Press.

Grix, Jonathan and Paul Michael Brannagan. 2016. "Of Mechanisms and Myths: Conceptualising States Soft Power Strategies through Sports Mega-Events." Diplomacy \& Statecraft 27(2): 251-272.

Hackbarth, James R. 2008. Soft Power and Smart Power in Africa. Ft. Belvoir: Defense Technical Information Center.

Harrison, Selig S. 2003. Korean Endgame: A Strategy for Reunification and U. S. Disengagement. Princeton, NJ, USA: Princeton University Press.

Henriksen, Thomas H. 2001. "Conceptualization and Definition - The Rise and Decline of Rogue States." Journal of International Affairs 54(2): 349.

Hsiao, Michael and A Yang. 2009. "Soft Power Politics in the Asia Pacific: Chinese and Japanese Quests for Regional Leadership." The Asia-Pacific Journal: Japan Focus 7(8).

Kalin, Ibrahim. 2011. "Soft Power and Public Diplomacy in Turkey." Perceptions: Journal of International Affairs 16(3).

Kalinowski, Thomas and Hyekyung Cho. 2012. "Korea's Search for a Global Role between Hard Economic Interests and Soft Power." European Journal of Development Research 24(2): 242-260.

Karadag, Haluk. 2017. "Forcing the Common Good: The Significance of Public Diplomacy in Military Affairs." Armed Forces \& Society 43(1): 72-91.

Kihl, Young Whan and Hong Nack Kim. 2006. North Korea: The Politics of 
Regime Survival: M.E. Sharpe.

Kroenig, Matthew, Melissa McAdam and Steven Weber. 2010. "Taking Soft Power Seriously." Comparative Strategy 29(5): 412-431.

Kwak, Tae-Hwan. 2010. "The Six-Party Talks and North Korea's Denuclearization: Evaluation and Prospects." Pacific Focus 25(2): 211-236.

Lam, Peng Er. 2007. "Japan's Quest for Soft Power: Attraction and Limitation." East Asia: An International Quarterly 24(4): 349-363.

Loh, Dylan. 2017. "Defending China's National Image and Defensive Soft Power:

The Case of Hong Kong's Umbrella Revolution." Journal of Chinese Political Science 22(1): 117-134.

Mattern, Janice Bially. 2005. "Why 'Soft Power' Isn't So Soft: Representational Force and the Sociolinguistic Construction of Attraction in World Politics." Millennium 33(3): 583-612.

McClory, Jonathan. 2015. The Soft Power 30 - A Global Ranking of Soft Power. Portland Communications.

McCormack, Gavan. 2004. Target North Korea: Pushing North Korea to the Brink of Nuclear Catastrophe. New York: Nation Books.

Melissen, Jan. 2005. The New Public Diplomacy: Soft Power in International Relations. Basingstoke; New York: Palgrave Macmillan.

Morgenthau, Hans J. 1985. Politics Among Nations: The Struggle for Power and Peace. New York: Alfred A. Knopf.

Noland, Marcus. 1997. "Why North Korea Will Muddle Through.” Foreign Affairs, July/August 1997.

Nye, Joseph. 2008. "Public Diplomacy and Soft Power." The Annals of the American Academy of Political and Social Science 616(1): 94-109.

Nye, Joseph S. 1990. Bound to Lead: The Changing Nature of American Power. New York: Basic Books.

Nye, Joseph S. 2006. Soft Power: The Means to Success in World Politics. New York: Public Affairs.

Oh, Kongdan and Ralph Hassig. 1999. "North Korea Between Collapse and Reform.” Asian Survey 392: 287-309.

Paradise, James F. 2009. "China and International Harmony: The Role of Confucius Institutes in Bolstering Beijing's Soft Power.” Asian Survey 49(4): 647-669.

Park, Kyung-Ae and Mark Bennett. 2014. "Engaging North Korea with HighCulture Soft Power: Knowledge-Sharing with Pyongyang.” Pacific Affairs 87 (1): 29-41.

Plavsak, Kristina. 2002. "Communicative Diplomacy for the 3rd Millennium." Journal of Political Marketing 1(2-3): 109-122.

Rose, Richard. 2005. Language, Soft Power and Asymmetrical Internet Communication. Oxford: Oxford Internet Institute.

Roselle, Laura, Alister Miskimmon and Ben O'Loughlin. 2014. "Strategic Narrative: 
A New Means to Understand Soft Power.” Media, War \& Conflict 7(1): 70-84. Saunders, Harold. 1991. "Officials and Citizens in International Relations: The Dartmouth Conference." In The Psychodynamics of International Relationships, Volume II: Unofficial Diplomacy at Work, edited by Vamik D Volka, Joseph V. Montville and Demetrios A. Julius. Lexington, Mass: Lexington Books.

Shambaugh, David. 2003. "China and the Korean Peninsula: Playing for the Long Term." The Washington Quarterly 26(2): 43-56.

Sigal, Leon V. 1999. Disarming Strangers: Nuclear Diplomacy with North Korea.

Princeton, NJ, USA: Princeton University Press.

Ślusarczyk, Zenon. 2010. The Role of the European Union in North Korea. Polityka Prywatności.

Smith, Hazel. 2000. "Bad, Mad, Sad or Rational Actor? Why the 'Securitization'

Paradigm Makes for Poor Policy Analysis of North Korea.” International Affairs 76(1): 111-132.

Snyder, Scott. 1999. Negotiating on The Edge: North Korean Negotiating Behavior.

Washington D.C: United States Insitute of Peace Press.

Strange, Susan. 2015. States and Markets: Bloomsbury Publishing.

Tsyganov, Andrei P. 2006. "If Not by Tanks, then by Banks?: The Role of Soft Power in Putin's Foreign Policy.” Europe-Asia Studies 58(7).

Van Ness, Peter. 2003. The North Korean Nuclear Crisis: Four-Plus-Two - An Idea Whose Time Has Come. Canberra: Department of International Relations, Australian National University.

Wagner, Christian. 2010. "India's Soft Power: Prospects and Limitations." India Quarterly 66(4): 333-342.

Wang, Hongying and Yeh-Chung Lu. 2008. "The Conception of Soft Power and its Policy Implications: a comparative study of China and Taiwan." Journal of Contemporary China 17(56): 425-447.

Wastnidge, Edward. 2015. "The Modalities of Iranian Soft Power: From Cultural Diplomacy to Soft War." PONL Politics 35(3-4): 364-377.

Wilson, Ernest. 2008. "Hard Power, Soft Power, Smart Power." The Annals of the American Academy of Political and Social Science 616(1): 110-124.

Woehrle, Lynne M. 1992. Social Constructions of Power and Empowerment: Thoughts from Feminist Approaches to Peace Research and Peace-making. Syracuse: Syracuse University Press.

Wu, Anne. 2005. "What China Whispers to North Korea." The Washington Quarterly 28(2): 35-48.

Zhebin, Alexander. 1995. "Russia and North Korea: an Emerging, Uneasy Partnership." Asian Survey 358: 726-739.

Zhu, Zhiqun. 2007. "Small Power, Big Ambition: South Korea's Role in Northeast Asian Security under President Roh Moo-hyun." Asian Affairs: An American Review 34(2): 67-86. 


\section{ENDNOTES}

1 The Korea Times, "Divided Korea Bridged by Reunions," August 16, 2000.

2 Associated Press International, "Germany Opens First Western Reading Room in North Korea," June 2, 2004.

3 KCNA, "Kim Jong Un Enjoys Basketball Game of DPRK, American Players," 28 February 2013; "Kim Jong Un Watches Basketball Game of DPRK, American Players," January 8, 2014.

4 See Sara van der Heide, “The German Library Pyongyang' project, available at http://www.theger manlibrarypyongyang.de [Last Accessed April 17, 2017].

5 Deutsche Welle, "Goethe-Institut to Close Center in North Korea on Censorship Claim," November 26, 2009.

6 Official website of the Pyongyang University of Science and Technology, available at http://www.pust.kr [Last Accessed April 17, 2017].

7 Personal interview with KFA India Head, November 30, 2015; Personal interview with KFA UK Head, November 26, 2015.

8 Japan Economic Newswire, "S. Korea Supports North's Bid for World Heritage Site," April 28, 1999.

9 Korea Times, "N. Korea Arirang Wins UNESCO Intangible Heritage Status,” November 27, 2014.

${ }_{10}$ Africa News, "Uganda; North Korea to Solve Police Housing Crisis," June 12, 2013.

11 The East African, "Uganda, Tanzania in trouble with UN over 'arms deals' with North Korea," April 12, 2014.

12 Thai News Service, "North Korea/Netherlands: N. Korean Restaurant Opens in Netherlands," February 6, 2012.

13 The Guardian, "Thirteen North Korean Restaurant Workers Defect to South Korea," April 8, 2016

${ }^{14}$ Artnetnews, "The North Korean Art Factory Cranking Out Soviet-Style Monuments," August 5, 2014.

15 BBC Monitoring Africa - Political, "North Korea to Assist in Building Army Museum in Tanzania," August 31, 2008

${ }^{16}$ The Independent, "Cambodia's Latest Attraction is a 'gift' from North Korea," 3 January 2014.

17 South East Asian News, "North Korea Built Angkor Panorama Museum Open for Public in Cambodia," January 19, 2016.

${ }^{18}$ United Nations Security Council 2321 (2016). Available at http://www.securitycouncilreport.org/ atf/cf/\%7B65BFCF9B-6D27-4E9C-8CD3-CF6E4FF96FF9\%7D/s res_2321.pdf [Last Accessed April 17, 2017].

${ }^{19}$ IHS Global Insight, "Pariahs Join Hands as Zimbabwe and North Korea Sign Healthcare Deal," August 11, 2006.

${ }^{20}$ IHS Global Insight, "Governments of Mexico and North Korea Sign Health Co-operation Agreement," November 6, 2009.

${ }^{21}$ See KOTRA, http://news.kotra.or.kr/kotranews/index.do [Last Accessed April 17, 2017]. 